Revta brasil. Bot., São Paulo, V.24, n.4 (suplemento), p.537-544, dez. 2001

\title{
Relação entre vegetação e solo em um gradiente florestal na Estação Ecológica do Panga, Uberlândia (MG) ${ }^{1}$
}

\author{
MARIA INÊS CRUZEIRO MORENO e IVAN SCHIAVINI ${ }^{2,3}$
}

(recebido: 4 de setembro de 2000; aceito: 30 de maio de 2001)

\begin{abstract}
Relationship between vegetation and soil in a forest gradient in the Panga Ecological Station, Uberlândia (MG)). The relationship between the soil characteristics and a forest gradient, formed by gallery forest, semideciduous forest and "cerradão", in the Panga Ecological Station, Uberlândia, MG, Brazil, was analysed. A total of 211 bulk soil samples were collected, from a depth of $0-20 \mathrm{~cm}$, and analysed for their physical (granulometric) and chemical (macronutrients and fertility parameters) characteristics. The phytophysiognomies differed statisticaly from each other for the variables calcium, magnesium, potassium, phosphorus, aluminium, saturation of aluminium, saturation of bases and organic matter, while other edaphic attributes were similar in pairs of phytophysiognomies. Some plant species were distributed in the forest gradient following the variation of soil physical-chemical composition, while others are apparently indifferent to the soil gradient. There is evidence that the soil represents an important role in the structuring of the vegetation along the studied forest gradient.

RESUMO - (Relação entre vegetação e solo em um gradiente florestal na Estação Ecológica do Panga, Uberlândia (MG)). Relacionou-se a composição física (granulometria) e química (macronutrientes e parâmetros de fertilidade) do solo com um gradiente florestal formado por mata de galeria, mata mesófila semidecídua de encosta e cerradão, na Estação Ecológica do Panga, Uberlândia - MG. Foram analisadas 211 amostras de solo, coletadas a uma profundidade de $0-20 \mathrm{~cm}$. As fitofisionomias são estatisticamente distintas entre si quanto a cálcio, magnésio, potássio, fósforo, alumínio, saturação por alumínio, saturação por bases e matéria orgânica, enquanto que, para outros atributos edáficos, podem ser encontrados pares fitofisionômicos semelhantes. Algumas espécies vegetais encontram-se distribuídas no gradiente florestal seguindo a variação da composição físico-química do solo, enquanto outras se apresentam indiferentes ao gradiente edáfico. Há evidências de que o solo representa um importante papel para a estruturação vegetal ao longo do gradiente florestal estudado.
\end{abstract}

Key words - Soil, forest gradient, soil-vegetation relationship

\section{Introdução}

As formações florestais estão entre as importantes fitofisionomias presentes no bioma cerrado, podendo estar associadas ou não a cursos d'água (Ribeiro \& Walter 1998). Esse tipo de formação pode ser encontrado de forma esparsa, como manchas inseridas no bioma cerrado, apenas em pequenas áreas onde os solos são mais férteis (Oliveira-Filho \& Ratter 1995). A relativa fertilidade do solo que sustenta esse tipo de formação faz com que esta se torne alvo de intensa exploração antrópica, não só para uso do solo sobre o qual ocorre, como também para a utilização de suas espécies para fins madeireiros.

1. Parte da dissertação de mestrado de M. I. C. Moreno.

2. Universidade Federal de Uberlândia, Instituto de Biologia, Caixa Postal 593, 38400-902 Uberlândia, MG, Brasil.

3. Autor para correspondência: schiavini@ufu.br
Apesar da crescente conscientização sobre a importância biológica das formações florestais, como abrigo para a fauna nos períodos secos, corredores de passagem para espécies silvestres e como filtro natural dos cursos d'água, pouco se sabe sobre as interações entre as comunidades vegetais e os fatores abióticos que sustentam estas fitofisionomias. Fatores como o clima (Cole 1992), diferenças no regime do lençol freático (Oliveira-Filho et al. 1994a), composição física e química do solo e/ou topografia (Ratter et al. 1978, Oliveira-Filho et al. 1994b, Haridasan et al. 1997, Oliveira-Filho et al. 1998) são considerados importantes na distribuição e estruturação de formações florestais no bioma cerrado.

Trabalhos têm sido feitos com o intuito de reconhecer a composição florística e os fatores que estariam determinando a ocorrência de matas de galeria e ciliar (Oliveira-Filho et al. 1989, OliveiraFilho et al. 1994a), matas semidecíduas (Araújo \& Haridasan 1997, Oliveira-Filho et al. 1997) e de cerradões (Araújo \& Haridasan 1988). 
Este trabalho faz parte de uma série de estudos sobre a ecologia de formações florestais do Brasil Central. Inicialmente foi feito levantamento fitossociológico da área, que se localiza na Estação Ecológica do Panga, Uberlândia, MG (I. Schiavini et al., dados não publicados). A partir desta amostragem das espécies arbóreas, estabelecidas no local, verificou-se que havia um gradiente florestal, formado por mata de galeria, mata mesófila semidecídua de encosta e cerradão, e que algumas espécies apresentavam-se distribuídas de forma a seguir algum padrão relacionado com o ambiente físico. A hipótese de que o solo estaria influenciando essa estruturação da comunidade foi levantada.

Sendo assim, o presente trabalho teve por objetivo analisar o solo com relação às suas características físicas e químicas, ao longo do gradiente florestal constituído por mata de galeria, mata mesófila de encosta e cerradão, e verificar a existência de relação entre variações na ocorrência de espécies vegetais arbóreas de formações florestais do bioma cerrado e os parâmetros medidos no solo (granulometria e composição química), no gradiente estudado, na Estação Ecológica do Panga, em Uberlândia - MG.

\section{Material e métodos}

A Estação Ecológica do Panga - EEP (figura 1) possui área de 409,5 ha e situa-se a $30 \mathrm{~km}$ ao sul do centro urbano do município de Uberlândia, Minas Gerais. Localiza-se entre as

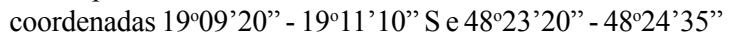
W, com altimetria variando de 750 a 830 m (Schiavini \& Araújo 1989).

Os solos da região de estudo são classificados como Latossolo Vermelho e Latossolo Vermelho-Amarelo, profundo, bem drenado e com textura acentuadamente arenosa (Schiavini 1997), e solos hidromórficos de textura arenosa, de mediana a intensamente ácidos, com características distróficas (Lima 1992). O clima, segundo a classificação de Köppen, é do tipo Aw, megatérmico, com verões chuvosos (de outubro a março) e inverno seco (de abril a setembro), com temperatura média anual de $22^{\circ} \mathrm{C}$ e pluviosidade anual de aproximadamente $1500 \mathrm{~mm}$ (Rosa et al. 1991).

A EEP apresenta diversos tipos fitofisionômicos encontrados na região dos cerrados do Brasil Central, tais como mata de galeria e mata mesófila de encosta, mata xeromórfica (cerradão), cerrado (sentido restrito), campo cerrado, campo sujo, campos úmidos e veredas (Schiavini \& Araújo 1989).

O gradiente florestal estudado é composto por três fitofisionomias contínuas, sendo mata de galeria (margeando o ribeirão do Panga), mata mesófila semidecídua de encosta e cerradão.

A mata de galeria é uma formação florestal que acompanha os rios de pequeno porte e córregos dos planaltos do Brasil Central, formando corredores fechados (galerias) sobre o curso d'água. As espécies são perenifólias, não apresentando caducifolia na estação seca. Apresenta altura média arbórea de 20 a 30 m, com sobreposição das copas, oferecendo cobertura de 70 a $95 \%$. Mesmo na época mais seca do ano apresenta alto teor de umidade em seu interior (Schiavini 1997, Ribeiro \& Walter 1998). Na área de estudo, foram encontradas 61 espécies arbóreas na mata de galeria. A mata mesófila de encosta, denominada mata seca por Ribeiro \& Walter (1998), caracteriza-se por apresentar diversos níveis de caducifolia durante o período de seca, fator este que contribui para o aumento da matéria orgânica no solo. Esta caducifolia é determinada em função do tipo de solo que a sustenta e da composição florística, sendo representada por três subtipos: mata seca sempre-verde, mata seca semidecídua e mata seca decídua (Ribeiro \& Walter 1998). A cobertura do estrato arbóreo pode chegar a $100 \%$ no período chuvoso e a altura máxima a $25 \mathrm{~m}$, na área de estudo. A riqueza florística, nesta área, foi de 116 espécies arbóreas. O cerradão caracterizase pela presença de espécies do cerrado sentido restrito e por espécies da mata, com riqueza total de 98 espécies arbóreas, na área estudada. $\mathrm{O}$ estrato arbóreo apresenta altura média de 8 a 15 metros, com dossel predominantemente contínuo e cobertura de 50 e $90 \%$, o que proporciona condições de luminosidade que favorecem a formação de estratos arbustivos e herbáceos diferenciados. A fisionomia do cerradão é perenifólia, apesar de algumas espécies apresentarem caducifolia em curtos e não coincidentes períodos durante a estação seca (Ribeiro \& Walter 1998).

A separação destas fitofisionomias foi feita por análise de agrupamentos UPGMA (média de grupo) utilizando o programa Fitopac 1 (Shepherd 1995). A medida de similaridade foi o índice de Soresen-Czekanowiski, aplicado à matriz de presença ou ausência das espécies nas parcelas amostradas (I. Schiavini et al., dados não publicados).

A área foi demarcada por oito transectos denominados de $\mathrm{A}$ $\mathrm{a} \mathrm{H}$, dispostos no sentido jusante do ribeirão e perpendicularmente às margens do mesmo, atravessando o gradiente florestal $\mathrm{e}$ terminando na borda da formação florestal contígua ao campo cerrado. Os transectos foram subdivididos em parcelas contínuas de $10 \times 10$ m que, após o resultado do agrupamento descrito acima, resultaram em 21 parcelas na mata de galeria, 150 na mata mesófila semidecídua de encosta e 40 no cerradão, em um total de 211 parcelas, cobrindo uma área de 2,11 ha (figura 1).

Em cada parcela, foram coletadas três amostras de solo, a uma profundidade 0 a $20 \mathrm{~cm}$, sendo uma no centro e duas em diagonal nos vértices da parcela, as quais constituíram uma amostra composta do solo da parcela. A análise granulométrica foi feita no Laboratório de Geomorfologia e Erosão de Solos da Universidade Federal de Uberlândia e a análise química foi feita no Laboratório de Análise de Solos do Departamento de Agronomia da Universidade Federal de Uberlândia. As análises de solo seguiram a rotina estabelecida em cada laboratório. 


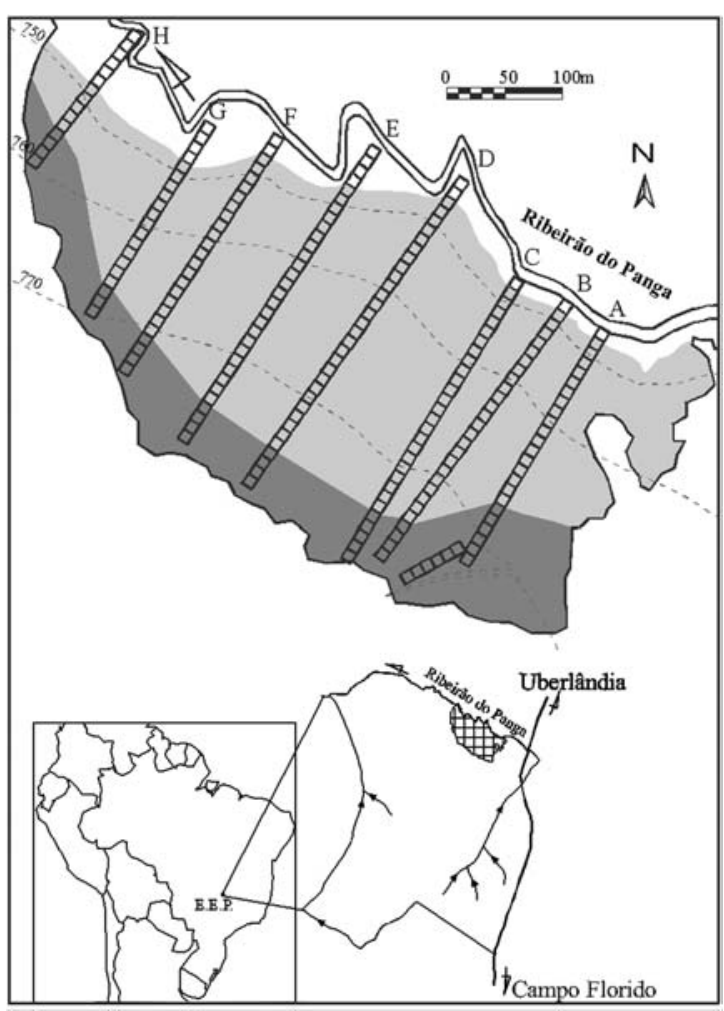

Figura 1. Localização geográfica da área de estudo. Gradiente florestal da Estação Ecológica do Panga, Uberlândia - MG. A a H Transectos; Drenagem $(\rightarrow)$; Formação florestal estudada (田); Mata de galeria ( $\mathbf{a}$ ); Mata mesófila semidecídua de encosta ( $\mathbf{\square})$; Cerradão ( $\mathbf{\square})$.

$\mathrm{Na}$ análise física, foram verificadas as porcentagens de cada fração granulométrica (areia grossa, areia fina, silte e argila), enquanto que, na análise química, foram verificados pH em água, concentrações de fósforo, potássio, alumínio, cálcio, magnésio e hidrogênio + alumínio, soma de bases, capacidade de troca catiônica efetiva (CTC), capacidade de troca catiônica a pH 7,0 $\left(\mathrm{CTC}_{\mathrm{pH}}\right)$, saturação por bases, saturação por alumínio e matéria orgânica.

Os testes de Shapiro-Wilk e Levenne foram utilizados para a verificação da existência de normalidade dos dados e homogeneidade entre as variâncias, para todos os parâmetros analisados. Uma vez que as variáveis não apresentaram normalidade e/ou homogeneidade, utilizou-se a análise da variância não-paramétrica para dois fatores, fitofisionomias e transectos, como uma extensão do teste de Kruskal-Wallis proposta por Scheirer et al. (1976, apud Zar 1984). O teste de Mann-Whitney foi utilizado para comparação entre as médias obtidas, duas a duas. A comparação dos transectos entre si não será apresentada neste trabalho, uma vez que as diferenças foram pequenas e não mostraram tendências que auxiliem na discussão dos resultados.

Como os parâmetros pedóficos apresentam-se distribuídos em um gradiente contínuo na área de estudo, utilizou-se o programa Surfer 6.01 para a confecção de mapas de intervalos de concentração e de variação dos fatores analisados no gradiente florestal.

\section{Resultados e Discussão}

Os resultados das análises química e física do solo encontram-se na tabela 1 e figuras 2 e 3 . Estes permitem classificar o solo das três fitofisionomias como de textura média (EMBRAPA 1999), acidez média com pH entre 5,0 e 5,9 (CFSEMG 1989) e com baixos teores de alumínio na mata mesófila semidecídua de encosta. As três fitofisionomias são distintas entre si significativamente quanto à concentração de cálcio, magnésio, potássio, fósforo e alumínio, e quanto à saturação por alumínio, saturação por bases e matéria orgânica.

Classes texturais, tanto finas quanto grossas, apresentaram-se homogeneamente distribuídas pelo gradiente florestal, exceto por uma pequena área de mata de galeria, que apresentou elevada porcentagem de argila e silte (figura 2). Os maiores teores de silte e areia grossa foram encontrados na mata mesófila e no cerradão, enquanto que, para argila, os maiores teores foram encontrados na mata de galeria e, para areia fina, as maiores médias foram encontradas na mata de galeria e no cerradão (tabela 1).

Com relação às características químicas do solo (tabela 1), na mata de galeria foram encontrados os maiores valores para fósforo, matéria orgânica e capacidade de troca catiônica (CTC a pH 7,0), enquanto na mata mesófila foram significativos os valores maiores para magnésio, potássio, saturação por bases e pH em água. O cerradão se destaca pelos maiores valores para alumínio e saturação por alumínio e os menores valores para CTC, saturação por bases, soma de bases e matéria orgânica.

A mata de galeria estudada apresenta condições edáficas variadas, com solos arenosos a argilosos, que propiciam o estabelecimento de populações vegetais adaptadas a cada micro ambiente formado.

Parcelas amostradas, que são classificadas como de textura média a argilosa e principalmente como argilosas, com encharcamento do solo durante os períodos úmidos, caracterizam-se como áreas que Ribeiro \& Walter (1998) denominaram de mata de galeria inundável. $O$ alto teor de partículas finas, presente no solo deste local (figura 2), possibilita 
Tabela 1. Valores médios + desvio padrão das características do solo analisadas nas três fitofisionomias do gradiente florestal na Estação Ecológica do Panga, Uberlândia - MG.

\begin{tabular}{|c|c|c|c|}
\hline Características & Mata de Galeria & Mata de Encosta & Cerradão \\
\hline \multicolumn{4}{|l|}{ Granulométricas } \\
\hline Argila $(\%)$ & $16,92 \pm 9,12 \mathrm{a}$ & $15,41 \pm 1,53 \mathrm{ab}$ & $13,30 \pm 3,13 b$ \\
\hline Silte $(\%)$ & $3,02 \pm 1,20 \mathrm{~b}$ & $4,12 \pm 1,44 \mathrm{a}$ & $5,56 \pm 4,32 \mathrm{a}$ \\
\hline Areia Fina $(\%)$ & $53,95 \pm 14,47 \mathrm{a}$ & $49,72 \pm 3,80 \mathrm{~b}$ & $50,75 \pm 5,05 \mathrm{a}$ \\
\hline Areia Grossa (\%) & $22,00 \pm 9,73 b$ & $30,93 \pm 3,76 \mathrm{a}$ & $32,18 \pm 3,85 a$ \\
\hline \multicolumn{4}{|l|}{ Químicas } \\
\hline Cálcio $\left(\mathrm{cmolc} . \mathrm{dm}^{-3}\right)$ & $3,92 \pm 1,82 \mathrm{a}$ & $3,86 \pm 1,10 \mathrm{a}$ & $1,06 \pm 0,96 \mathrm{~b}$ \\
\hline Magnésio $\left(\mathrm{cmolc} . \mathrm{dm}^{-3}\right.$ ) & $1,18 \pm 0,53 \mathrm{~b}$ & $1,44 \pm 0,40 \mathrm{a}$ & $0,49 \pm 0,46 \mathrm{c}$ \\
\hline CTC $\left(\mathrm{cmolc} . \mathrm{dm}^{-3}\right)$ & $5,48 \pm 2,16 a$ & $5,60 \pm 1,33 a$ & $2,10 \pm 1,25 b$ \\
\hline CTC a pH 7,0 (cmolc. $\left.\mathrm{dm}^{-3}\right)$ & $10,47 \pm 3,54 \mathrm{a}$ & $8,80 \pm 1,06 \mathrm{~b}$ & $6,03 \pm 1,73 c$ \\
\hline $\mathrm{H}+\mathrm{Al}\left(\mathrm{cmolc} . \mathrm{dm}^{-3}\right)$ & $5,14 \pm 2,07 \mathrm{a}$ & $3,20 \pm 0,97 \mathrm{~b}$ & $4,28 \pm 0,68 \mathrm{a}$ \\
\hline Alumínio $\left(\mathrm{cmolc} \cdot \mathrm{dm}^{-3}\right)$ & $0,18 \pm 0,03 \mathrm{~b}$ & $0,02 \pm 0,08 \mathrm{c}$ & $0,36 \pm 0,25 \mathrm{a}$ \\
\hline Soma de bases $\left(\mathrm{cmolc}^{\left.-\mathrm{dm}^{-3}\right)}\right.$ & $5,30 \pm 2,23 \mathrm{a}$ & $5,59 \pm 1,37 \mathrm{a}$ & $1,72 \pm 1,44 b$ \\
\hline Potássio $\left(\mathrm{mg} \cdot \mathrm{dm}^{-3}\right)$ & $80,30 \pm 17,85 b$ & $108,89 \pm 27,79 a$ & $65,17 \pm 22,98 \mathrm{c}$ \\
\hline Fósforo $\left(\mathrm{mg} \cdot \mathrm{dm}^{-3}\right)$ & $5,34 \pm 3,26 \mathrm{a}$ & $2,25 \pm 1,35 \mathrm{~b}$ & $1,65 \pm 0,95 \mathrm{c}$ \\
\hline Saturação por alumínio (\%) & $4,00 \pm 3,66 \mathrm{~b}$ & $0,65 \pm 2,51 \mathrm{c}$ & $28,05 \pm 24,09 \mathrm{a}$ \\
\hline Saturação por bases (\%) & $50,38 \pm 10,93 \mathrm{~b}$ & $63,08 \pm 11,18 \mathrm{a}$ & $24,92 \pm 14,89 \mathrm{c}$ \\
\hline Matéria orgânica $\left(\mathrm{g} \cdot \mathrm{kg}^{-1}\right)$ & $4,31 \pm 2,00 \mathrm{a}$ & $3,28 \pm 0,58 \mathrm{~b}$ & $2,38 \pm 0,76 \mathrm{c}$ \\
\hline PH em água & $5,20 \pm 0,35 \mathrm{~b}$ & $5,80 \pm 0,30 a$ & $5,08 \pm 0,27 \mathrm{~b}$ \\
\hline
\end{tabular}

Médias seguidas por letras iguais, nas linhas, não diferem significativamente pelo teste de Mann-Whitney $(\mathrm{p}<0,05)$

o acúmulo de matéria orgânica, cálcio e fósforo, resultando em alto valor de capacidade de troca catiônica, valores relativamente reduzidos de $\mathrm{pH}$, além de traços de alumínio (figura 3). O microambiente formado por estas características propicia o estabelecimento de espécies características a estes locais de mata de galeria.

Nas áreas de saturação hídrica, presentes na mata de galeria, há maior ocorrência de Talauma ovata St. Hil. e Calophyllum brasiliense Camb. Comparando os dados de solo com os mapas de distribuição de espécies feitos por Silva (2001), constata-se que Luehea divaricata Mart. \& Zucc. e Protium heptaphyllum (Aubl.) March podem ser consideradas como preferenciais às áreas de mata de galeria, por apresentarem maior ocorrência nas parcelas com esta característica aqui discutida. Essas parcelas podem corresponder ao que Schiavini (1997) designou como meio da mata de galeria (microambiente com solo hidromórfico, alta porcentagem de argila e saturação hídrica causada por inundações periódicas, sobretudo na estação chuvosa) e ao que Silva (2001) indicou como áreas depressionárias, com inundações periódicas. Entre as espécies discutidas anteriormente, apenas Talauma ovata St. Hil. e Calophyllum brasiliense
Camb. foram amostradas exclusivamente na mata de galeria por I. Schiavini et al. (dados não publicados).

Florestas semidecíduas são caracterizadas por serem encontradas em solos mais profundos e férteis (Oliveira-Filho et al. 1994b), o que determina o estabelecimento de uma flora típica desses ambientes, uma vez que a fertilidade do solo, provavelmente, exerce papel importante na diferenciação da distribuição de espécies vegetais (Oliveira-Filho et al. 1997). Os resultados obtidos neste trabalho confirmam o exposto acima, uma vez que o solo de mata mesófila, que é composta por espécies com diferentes níveis de caducifolia, apresentou maior fertilidade, caracterizada pela alta saturação por bases (tabela 1). Correspondendo a esta característica do solo, verifica-se a ocorrência de espécies com distribuição exclusiva na mata mesófila, tais como Acrocomia aculeata (Jacq.) Lodd, Sweetia fruticosa Spreng. e Cariniana estrelensis (Raddi) Kuntze (I. Schiavini et al., dados não publicados).

Em trabalho realizado na mesma área, Araújo \& Haridasan (1997) encontraram valores de cálcio bem mais elevados do que os encontrados nesta pesquisa. Este fato talvez seja devido a uma 

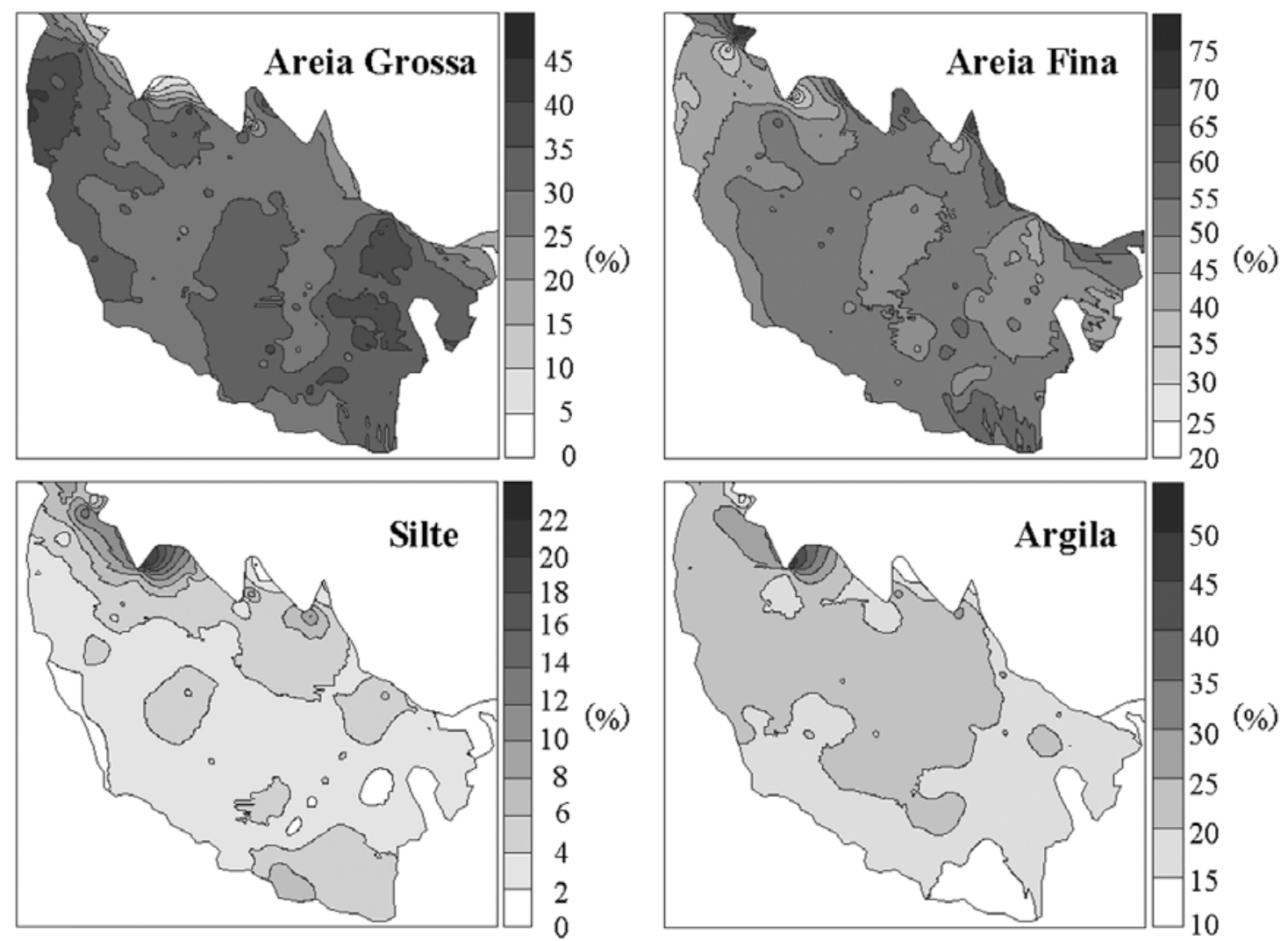

Figura 2. Faixa de distribuição granulométrica no gradiente florestal da Estação Ecológica do Panga (Uberlândia, MG). Distribuição ampliada a partir dos pontos de amostragem, utilizando-se o programa Surfer.

amostragem em duas diferentes profundidades, correspondentes aos horizontes A e A3 $(0-8 \mathrm{~cm} \mathrm{e}$ $8-64 \mathrm{~cm}$, respectivamente). Nesses horizontes, foram encontrados, em média, 8,37 cmolc. $\mathrm{kg}^{-1} \mathrm{e}$ 3,15 cmolc. $\mathrm{kg}^{-1}$ de cálcio, respectivamente, caracterizando um solo bem mais fértil do que o aqui estudado (profundidade $0-20 \mathrm{~cm}$, independente do horizonte), sendo encontrada uma concentração de cálcio, em média, de 3,86 cmolc. $\mathrm{dm}^{-3}$. Apesar da diferença encontrada entre os valores de concentração nos dois trabalhos, os solos, em ambos, apresentam características de alta fertilidade, o que pode ter possibilitado o estabelecimento de espécies mais exigentes em relação a essas características, como Anadenanthera colubrina (Benth.) Brenan var. cebil (Griseb.) Altschul, indicada por Ratter et al. (1978) como uma espécie tipicamente encontrada em solos mais férteis.
Entre as espécies com maior valor de importância (IVI) na mata mesófila (Schiavini et al., dados não publicados) e que apresentam distribuição em mais de uma fitofisionomia, apenas Chrysophyllum marginatum (Hook. \& Arn.) Radlk. apresenta distribuição relacionada ao gradiente de fertilidade do solo ao longo do gradiente florestal, sendo mais encontrada nas áreas com maior fertilidade.

De acordo com os resultados obtidos (tabela 1), a área de cerradão analisada classifica-se como sendo um cerradão distrófico, com elevada concentração de alumínio e baixa concentração de cálcio e magnésio disponíveis no solo (figura 3). Dentre as espécies encontradas tipicamente nessa formação florestal, como Qualea grandiflora Mart., Q. multiflora Mart., Q. parviflora Mart. e Vochysia tucanorum (Spr.) Mart., apenas Q. grandiflora e V.tucanorum também foram amostradas, porém 

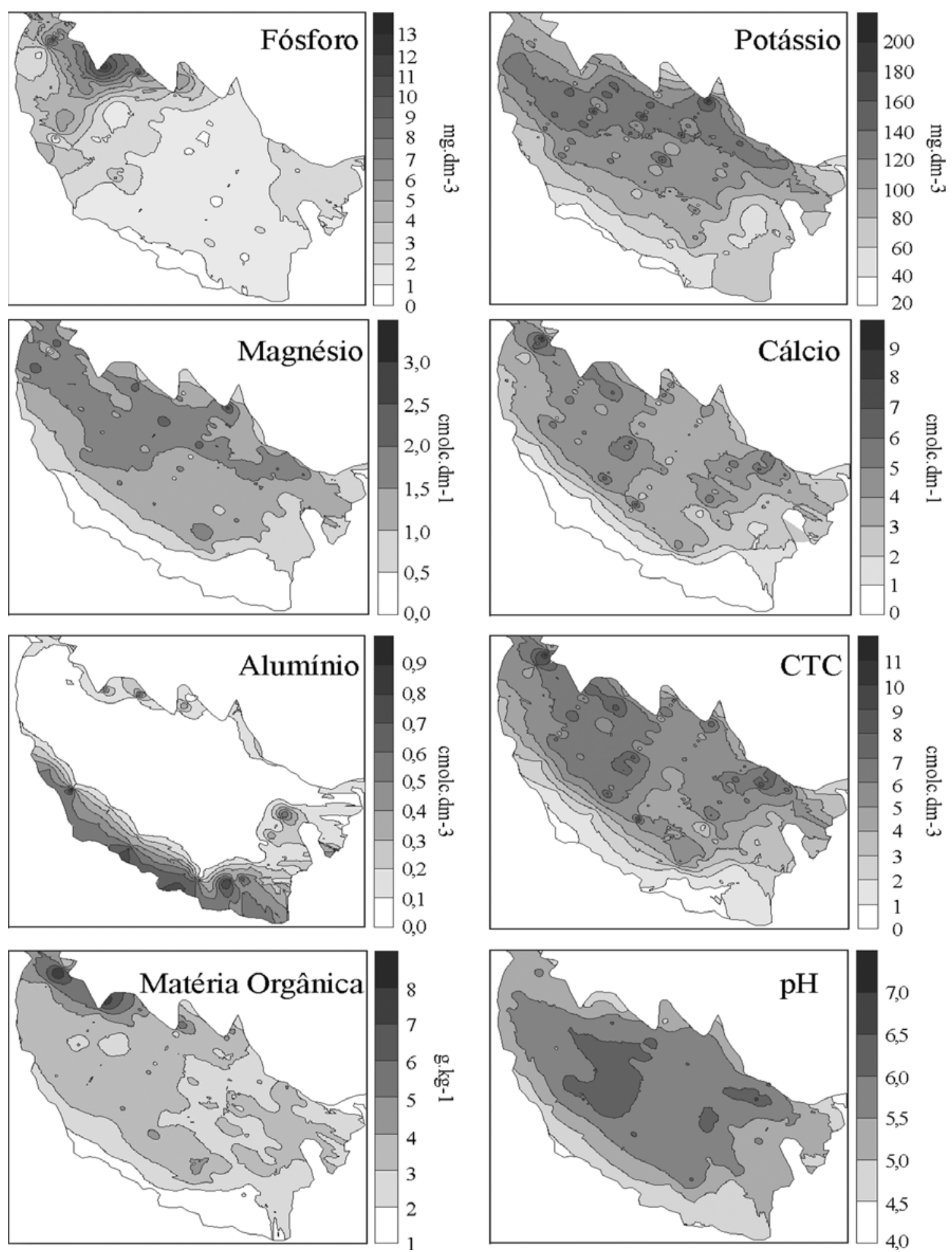

Figura 3. Faixa de distribuição dos parâmetros químicos no gradiente florestal da Estação Ecológica do Panga (Uberlândia, MG). Distribuição ampliada a partir dos pontos de amostragem, utilizando-se o programa Surfer. 
com poucos indivíduos, na área classificada floristicamente como mata mesófila por I. Schiavini et al. (dados não publicados). Tais indivíduos ocorreram em parcelas localizadas na transição entre as duas fisionomias, onde foi quantificado baixo teor de alumínio.

Nas demais parcelas de cerradão que apresentam características de solo distrófico (valores médios de saturação por bases em média inferiores a $50 \%$, menores concentrações médias de cálcio e magnésio e maiores teores de alumínio e saturação por alumínio (tabela 1)), observou-se um mosaico de espécies que foram amostradas por I. Schiavini et al. (dados não publicados) exclusivamente nestas parcelas, incluindo-se Annona crassiflora Mart., Didymopanax macrocarpum (C \& S) Seem, Caryocar brasiliensis Camb., Kielmeyera coriacea (Spr.) Mart., Stryphnodendron polyphyllum Mart., Q. multiflora e Q. parviflora, entre outras, além de espécies comuns a outras fitofisionomias, como Senna sylvestris Vell., Pseudobombax tomentosum (Mart. \& Zucc.) A. Robyns e Xylopia aromatica (Lam.) Mart.

Silva (2001), em estudo sobre a microtopografia na área em questão, observou que as parcelas de cerradão do transecto H ocupam uma posição topográfica inferior às demais parcelas desta fitofisionomia, amostradas nos demais transectos. Este fato serve como subsídio para explicar a diferença quantitativa em nutrientes, encontrada nesse local, em relação às demais áreas de cerradão amostradas (maiores teores de cálcio, magnésio, fósforo e potássio e menores valores para alumínio e saturação por alumínio). Segundo Johnston (1992), cátions em solução são transportados e aumentam a concentração, à medida que se aproximam das posições inferiores do relevo. O inverso desta situação ocorre com alumínio, que tende a se concentrar nas regiões mais elevadas do relevo, por não acompanhar o movimento de precipitação dos demais cátions, como sugerido por Chen et al. (1997).

Indivíduos de Copaifera langsdorffii Desf. foram amostrados em todas as fisionomias do gradiente estudado, indicando uma ampla aptidão da espécie em ocupar vários ambientes edáficos. Oliveira-Filho et al. (1994b) e Schiavini (1997) também amostraram esta espécie em mata semidecídua montana e mata de galeria, respectivamente. Esta amplitude na ocupação de ambientes pôde ser verificada, também, para indivíduos de Tapirira guianensis Aubl. (Anacardiaceae), que apresentaram ampla distribuição no gradiente florestal. Silva (2001) observou, também, que a distribuição desta espécie não se correlaciona com fatores microtopográficos da área.

O gradiente de fertilidade na área de estudo, representado pelos valores para saturação por bases e soma de bases, indica a seqüência mata mesófila semidecídua de encosta $>$ mata de galeria $>$ cerradão. A menor fertilidade no cerradão é justificada pela presença de maior teor de alumínio no solo, que determina menor disponibilidade de nutrientes para a vegetação (Araújo \& Haridasan 1988). A fertilidade intermediária observada na mata de galeria parece ser conseqüência do processo de lavagem que este solo sofre, em decorrência dos períodos de cheia e transbordamento do curso d'água.

A partir dos resultados obtidos, observa-se que o solo é um dos fortes fatores determinantes da distribuição da vegetação no gradiente estudado, provavelmente associado à disponibilidade de água e à interferência da luz em regiões de borda e em locais em que a sazonalidade climática forma clareiras de deciduidade.

Agradecimentos - Agradecemos à coordenação do curso de mestrado em Ecologia e Conservação de Recursos Naturais (COPEC), pelo apoio à pesquisa; à CAPES, pela concessão da bolsa de mestrado à primeira autora, que subsidiou o desenvolvimento deste trabalho; à Profa. Dra. Marli Ranal pela ajuda no tratamento dos dados, leitura e sugestões ao trabalho; ao Edivane Cardoso da Silva, pela leitura e sugestões.

\section{Referências bibliográficas}

ARAÚJO, G.M. \& HARIDASAN, M. 1988. A comparison of the nutritional status of two forest communities on mesotrophic and dystrophic soils in Central Brazil. Soil Science and Plant Analysis 19:1075-1089.

ARAÚJO, G.M. \& HARIDASAN, M. 1997. Estrutura fitossociológica de duas matas mesófilas semidecíduas, em Uberlândia, Triângulo Mineiro. Naturalia 22:115-129.

CHEN, Z., HSIEH, C., JIANG, F., HSIEH, H. \& SUN, I.1997. Relations of soil properties to topography and vegetation in a subtropical rain forest in southern Taiwan. Plant Ecology 132:229-241.

COLE, M.M. 1992. Influence of physical factors on thenature and dynamics of forest-savanna boundaries. In Nature and dynamics of forest-savanna boundaries (P.A. Furley, J. Proctor \& J.A. Ratter, eds.). Chapman \& Hall, London, p.63-75. 
CFSEMG - Comissão de Fertilidade do Solo do Estado de Minas Gerais. 1989. Recomendações para o uso de corretivos e fertilizantes em Minas Gerais. $4^{\text {a }}$ aproximação. Empresa de Pesquisa Agropecuária de Minas Gerais, Lavras (MG).

EMBRAPA - Empresa Brasileira de Pesquisa Agropecuária.1999. Sistema brasileiro de classificação de solos. $1^{\text {a }}$ ed. EMBRAPA Solos, Rio de Janeiro.

HARIDASAN, M., SILVA JR., M.C., FELFILI, J.M., REZENDE, A.V. \& SILVA, P.E.N. 1997. Gradient analysis of soil properties and phytosociological parameters of some gallery forests on the Chapada dos Veadeiros in the cerrado region of Central Brazil. In Proceedings of the international symposium on assessment and monitoring of forests in tropical dry regions with special reference to gallery forests (J. ImanãEncinas. \& C. Kleinn, eds.). Universidade de Brasília, Brasília, p.259-275.

JOHNSTON, M.H. 1992. Vegetation relationships in a tabonuco forest community in the Luquillo Mountais of Puerto Rico. Journal of Tropical Ecology 8:253-263.

LIMA, S.C. 1992. Mapeamento dos solos da bacia do ribeirão Panga. Sociedade \& Natureza 4:77-84.

OLIVEIRA-FILHO, A.T., SHEPHERD, G.J., MARTINS, F.R. \& STUBBLEBINE, W.H. 1989. Environmental factors affecting physionomic and floristic variation in an area of cerrado in Central Brazil. Journal of Tropical Ecology 9:413-431.

OLIVEIRA-FILHO, A.T., ALMEIDA, R.J., MELLO, J.M. \& GAVILANES, J.M. 1994a. Estrutura fitofisiológica e variáveis ambientais em um trecho de mata ciliar do córrego Vilas Boas, Reserva Biológica do Poço Bonito, Lavras (MG). Revista Brasileira de Botânica 17:67-85.

OLIVEIRA-FILHO, A.T., VILELA, E.A., GAVILANES, J.M. \& CARVALHO, D.A. 1994b. Comparison of the woody flora and soils of six areas of montane semideciduous forest in southern Minas Gerais, Brazil. Edinburgh Journal of Botany 51:355-389.

OLIVEIRA-FILHO, A.T. \& RATTER, J.A. 1995. A study of the origin of Central Brazilian forests by the analysis of plant species distribution patterns. Edinburgh Journal of Botany 52:141-194.
OLIVEIRA-FILHO, A.T., CURI, N., VILELA, E.A. \& CARVALHO, D.A. 1997. Tree species distribution along soil catenas in a riverside semideciduous forest in southeastern Brazil. Flora 192:47-64.

OLIVEIRA-FILHO, A.T., CURI, N., VILELA, E.A. \& CARVALHO, D.A. 1998. Effects of canopy gaps, topography and soils on the distribution of woody species in a Central Brazilian deciduous dry forest. Biotropica 30:362-375.

RATTER, J.A., ASKEW, G.P., MONTGOMERY, R.F. \& GIFFORD, D.R. 1978. Observations on forests of some mesotrophic soils in central Brazil. Revista Brasileira de Botânica 1:47-58.

RIBEIRO, J.F. \& WALTER, B.M.T. 1998. Fitofisionomias do bioma cerrado. In Cerrado: ambiente e flora (S.M. Sano \& S.P. Almeida, eds). EMBRAPA-CPAC, Planaltina, p.89-166.

ROSA, R., LIMA, S.C. \& ASSUNÇÃO, W.L. 1991. Abordagem preliminar das condições climáticas de Uberlândia (MG). Sociedade \& Natureza 3:91-108.

SCHIAVINI, I. \& ARAÚJO, G.M. 1989. Considerações sobre a vegetação da Reserva Ecológica do Panga (Uberlândia). Sociedade \& Natureza 1:61-65.

SCHIAVINI, I. 1997. Environmental characterization and groups of species in gallery forests. In Proceedings of the international symposium on assessment and monitoring of forests in tropical dry regions with special reference to gallery forests (J. Imanã-Encinas \& C. Kleinn, eds.). Universidade de Brasília, Brasília, p.107-116.

SHEPHERD, G.J. 1995. FITOPAC 1: Manual do usuário. Universidade Estadual de Campinas, Campinas.

SILVA, E.C. 2001. Relação entre distribuição de espécies vegetais arbóreas e a microtopografia em um gradiente florestal na Estação Ecológica do Panga (Uberlândia MG). Dissertação de mestrado, Universidade Federal de Uberlândia, Uberlândia.

ZAR, J.H. 1984. Bioestatistical analysis. Pratice Hall Inc., New Jersey. 